\title{
Faktor-faktor yang Mempengaruhi Kontraktur Sendi Lutut pada Penanganan Fraktur Femur Secara Operatif dan Non Operatif di RS. M. Djamil Padang
}

\author{
Yandri $\mathrm{E}^{\star}$, Manjas $\mathrm{M}^{\star \star}$, Rahmadian $\mathrm{R}^{\star \star}$, Erkadius ${ }^{\star \star \star}$
}

Abstrak

Kontraktur sendi lutut merupakan salah satu komplikasi yang sering muncul pada penderita fraktur femur. Selama bulan Oktober dan November 2011 didapatkan 81 kasus fraktur femur dan hanya 38 kasus yang memenuhi kriteria inklusi penelitian yaitu 20 kasus ditatalaksana dengan operatif dan 18 kasus lagi ditatalaksana dengan non operatif. Pada hasil penelitian ini, kejadian kontraktur sendi lutut berdasarkan usia tidak berbeda jauh, dimana kejadian kontraktur pada usia 13-20 tahun ditemukan 9 kasus ( 23,7 \%) dan pada usia $>21$ tahun ditemukan 11 kasus (28,9\%). Kekakuan/ kontraktur sendi lutut banyak ditemukan pada laki-laki sebanyak 13 kasus $(34,2 \%)$ dan pada perempuan ditemukan kekakuan sendi lututnya sebanyak 7 kasus (18,4 \%). Dari hasil penelitian ini kami menemukan kekakuan sendi lutut pada terapi operatif sebanyak 5 kasus (13,2 \%) dan non operatif ditemukan sebanyak 15 kasus.( 39,5\%).

Kata kunci: Fraktur femur, kontraktur, terapi operatif dan non operatif

\begin{abstract}
Contracture of the knee joint is one of the complications that often arise in patients with femur fractures. During October to November 2011 found 81 cases of femoral fracture and only 38 cases that met the study inclusion criteria, with 20 cases treated by operative and another 18 cases treated by non-operative. In this study, the incidence of knee joint contracture does not vary much by age, where the incidence of contractures at the age of 13-20 years found 9 cases (23.7\%) and age> 21 years was found 11 cases (28.9\%). Stiffness / knee joint contractures are common in men were 13 cases (34.2\%) and in women were found 7 cases (18.4\%). From this research we found the stiffness of the knee joint in operative therapy by 5 cases (13.2\%) and non-operative therapy found 15 cases. (39.5\%). Keywords:Femur Fracture, contractures, operative and non-operative therapy
\end{abstract}

Affiliasi penulis :

*Residen Bagian Ilmu Bedah RS. M. Djamil/FK UNAND Padang

** Staf Bagian IImu Bedah RS. M. Djamil/FK UNAND Padang

***Bagian Fisiologi FK UNAND Padang

Korespondensi :Yendri E

\section{LATAR BELAKANG}

Kontraktur sendi lutut merupakan salah satu komplikasi yang sering muncul pada penderita fraktur femur. Hal ini biasanya disebabkan ketidakpatuhan penderita untuk mengerjakan terapi latihan yang merupakan salah satu penanganan pasca tindakan. Kontraktur terjadi akibat keterbatasan sendi, fibrosis jaringan penyokong, otot dan kulit. Pencegahan terjadinya kontraktur itu sendiri ada berbagai macam seperti mencegah infeksi dan mengikuti terapi latihan. Dari literatur penyebab utama kontraktur adalah tidak ada atau kurangnya mobilisasi sendi akibat suatu keadaan antara lain ketidakseimbangan kekuatan otot, penyakit neuromuskular, penyakit degenerasi, luka bakar, luka trauma yang luas, inflamasi, dan penyakit kongenital. Dari semua penyebab kontraktur diatas, penyebab terbanyak adalah karena ketidakpatuhan penderita terhadap anjuran dokter untuk mengerjakan terapi latihan sendi lutut dan otot. Hal ini mengakibatkan gangguan untuk kegiatan sehari-hari pada penderita seperti shalat dan lain-lain. ${ }^{2}$

Dari observasi yang dilakukan oleh peneliti selama 2 bulan di poliklinik ortopedi RS. M Jamil Padang terhadap kunjungan pasien pasca tindakan fraktur femur banyak ditemukan terdapatnya kontraktur sendi lutut, mulai dari derajat ringan sampai berat. Berdasarkan hal demikian, peneliti ingin mengetahui seberapa besar angka kejadian kontraktur sendi lutut pada penanganan fraktur femur secara operatif dan non operatif di RS. M. Djamil Padang.

\section{METODE}

Rancangan penelitian bersifat retroprospektif dengan mengambil data pasien dan mengobservasi komplikasi yang ditimbulkan karena terapi non operatif dan operatif setelah 1 atau 2 tahun. Data dianalisa dengan membandingkan keadaan pasien secara parametrik. Semua data hasil pengobatan dibuat tabulasi data. Analisa data dilakukan secara deskriptif.

Data pasien yang didapat dari rekam medis di temukan 81 kasus fraktur femur $1 / 3$ tengah. Kriteria Inklusi terdiri dari 18 orang pasien yang di lakukan penanganan non operatif dan 20 orang pasien yang dilakukan penanganan operatif atas indikasi fraktur femur 1/3 tengah di RS M. Djamil Padang

Penelitian dilakukan di Poliklinik Orthopaed Rumah Sakit M Djamil Padang serta kunjungan ke rumah pasien selama bulan Oktober 2011 dan November 2011.

\section{HASIL PENELITIAN}

Telah dilakukan penelitian secara retrospektif dengan mengambil data pasien fraktur femur $1 / 3$ tengah yang ditalaksana dengan operatif dan non operatif yang di kumpulkan dari data rekam medik RSUP Dr.M.Djamil Padang dan setelah 1 atau 2 
tahun, dipantau kontraktur sendi lutut dengan mengunjungi pasien ke rumahnya.

Pada Penelitian ini didapatkan didapatkan data pasien dari rekam medik RS M. Djamil Padang dengan total pasien sebanyak 81 orang, dimana 38 orang diantaranya yang memenuhi kriteria penelitian ini terdiri dari 20 orang fraktur femur yang ditatalaksana dengan operatif dan 18 orang lainnya yang ditatalaksana dengan non operatif. Kemudian dilakukan kunjungan ke rumah pasien rumah dan dilakukan penilaian derajat lingkar gerak sendi.

Data yang didapat kemudian diolah dengan komputer dan dilakukan uji statistik non-parametrik (Chi square atau Fisher exact test, dengan $\mathrm{P}=0,05$ ditentukan sebagai batas kemaknaan. Data disajikan dalam bentuk tabel.

Dari penelitian ini didapatkan hasil sebagai berikut :

Tabel 1. Karakteristik pasien kontraktur sendi lutut

\begin{tabular}{lcc}
\hline Karakteristik & $\begin{array}{c}\text { Jumlah } \\
(\mathbf{n = 3 8})\end{array}$ & Persen \\
\hline $\begin{array}{l}\text { Jenis kelamin } \\
\text { Laki-laki }\end{array}$ & 26 & 68,4 \\
$\begin{array}{l}\text { Perempuan } \\
\text { Usia }\end{array}$ & 12 & 31,6 \\
$13-20$ & 19 & 50 \\
$>20$ & 19 & 50 \\
Tindakan & & \\
ORIF & 18 & 47,4 \\
Perkin & 20 & 52,6 \\
Pendidikan & 18 & 47,4 \\
$\begin{array}{l}\text { Rendah } \\
\text { Tinggi }\end{array}$ & 20 & 52,6 \\
Pengetahuan & & 2,6 \\
Kurang & 1 & 97,4 \\
Baik & 37 & \\
\hline
\end{tabular}

Tabel 2: Distribusi usia terhadap derajat kontraktur sendi lutut

\begin{tabular}{|c|c|c|c|}
\hline \multirow[t]{2}{*}{ Kontraktur } & \multicolumn{2}{|c|}{ Usia (tahun) } & \multirow[b]{2}{*}{ Total } \\
\hline & $13-20$ & $21 />$ & \\
\hline $\mathrm{Ya}$ & 9 & 11 & 20 \\
\hline Tidak & 10 & 8 & 18 \\
\hline Total & 19 & 19 & 38 \\
\hline $\begin{array}{l}\text { Chi S } \\
\text { Pada } \\
20 \text { orang yan } \\
\text { kontraktur. Tic } \\
\text { antara distribu } \\
\text { sendi lutut ( } C \\
\text { mana terlihat } p\end{array}$ & $\begin{array}{l}0.422, \\
\text { bel ini } \\
\text { rontrakt } \\
\text { terdap } \\
\text { usia de } \\
\text { square } \\
\text { a tabel }\end{array}$ & $\begin{array}{l}5 \\
\text { sarkan } \\
18 \\
\text { ungar } \\
\text { deraja } \\
422 ;\end{array}$ & $\begin{array}{l}\text { a didapatkan } \\
\text { g yang tidak } \\
\text { ig bermakna } \\
\text { traktur pada } \\
\text { 05), sebagai }\end{array}$ \\
\hline
\end{tabular}

Tabel 3: Distribusi Jenis tindakan dengan kontraktur sendi lutut

\begin{tabular}{llll}
\hline Kontraktur & \multicolumn{3}{c}{ Jenis } \\
\hline & ORIF & Perkin & Total \\
\hline Ya & 5 & 15 & 20 \\
Tidak & 15 & 3 & 18 \\
\hline Total & 20 & 18 & 38
\end{tabular}

Chi sq = 10.967 dengan koreksi Yates; $P<0,01$

Pada tabel ini didapatkan pasien yang ditindak dengan operatif sebanyak 20 orang dan ditindak dengan non operatif sebanyak 18 orang, sehingga dapat disimpulkan bahwa terdapat hubungan yang bermakna pada distribusi jenis tindakan terhadap derajat kontraktur sendi lutut (chi square=10,967; $\mathrm{P}<0,01)$, sebagai mana terlihat pada tabel 3

Tabel 4: Distribusi jenis kelamin terhadap kontraktur sendi lutut

\begin{tabular}{llll}
\hline Kontraktur & \multicolumn{3}{l}{ Sex } \\
\hline & Laki-laki & Perempuan & Total \\
\hline Ya & 13 & 7 & 20 \\
Tidak & 13 & 5 & 18 \\
\hline Total & 26 & 12 & 38 \\
\hline \multicolumn{5}{r}{ Chi sq $=0.229 ; P>0.05$}
\end{tabular}

Pada tabel ini didapatkan kejadian kontraktur pada laki-laki sebanyak 26 orang dan pada perempuan sebanyak 12 orang. Tidak terdapat terdapat hubungan yang bermakna antara jenis kelamin dengan derajat kontraktur sendi lutut (chi square $=0,229 ; P>0,05$ ), sebagai mana terlihat pada tabel 4

Tabel 5: Distribusi perbedaan waktu setelah tindakan terhadap kontraktur sendi lutut

\begin{tabular}{lll}
\hline Kontaktur & Waktu & Total \\
& & \\
Ya & 20 & 20 \\
Tidak & 18 & 18 \\
& & \\
\hline Total & 38 & \\
\hline
\end{tabular}

Pada tabel ini didapatkan 20 orang yang mengalami kontraktur dan 18 orang yang tidak mengalami kontraktur.

Tabel 6: Distribusi jenis kelamin terhadap perilaku

\begin{tabular}{llll}
\hline Perilaku & \multicolumn{3}{l}{ Sex } \\
\hline & Laki-laki & Perempuan & Total \\
\hline Kurang & 13 & 3 & 16 \\
Baik & 13 & 9 & 22 \\
\hline Total & 26 & 12 & 38 \\
\hline
\end{tabular}

Chi sq $=1.204$ dengan koreksi Yates; $P<0,01$ 
Pada tabel ini didapatkan pada laki-laki sebanyak 26 orang dan pada perempuan sebanyak 12 orang, dan tidak terdapat hubungan yang bermakna antara jenis kelamin dengan perilaku (chi square $=1,204 ; P>0,05)$, sebagai mana terlihat pada tabel 6.

Tabel 7: Distribusi jenis kelamin terhadap sikap

\begin{tabular}{llll}
\hline Sikap & & Sex & \\
\cline { 1 - 3 } & Laki-laki & Perempuan & Total \\
\hline Tidak & & 1 & 1 \\
Patuh & 26 & 11 & 37 \\
\hline Total & 26 & 12 & 38 \\
\hline & P Fisher $=0.316$ & &
\end{tabular}

Pada tabel ini didapatkan pada laki-laki sebanyak 26 orang dan pada perempuan sebanyak 12 orang, Tidak terdapat hubungan bermakna antara jenis kelamin terhadap sikap ( $\mathrm{P}$ Fisher 0,316; $P>0,05)$, sebagai mana terlihat pada tabel 7 .

Tabel 8: Distribusi jenis kelamin terhadap pengetahuan

\begin{tabular}{llll}
\hline \multicolumn{1}{c}{ Pengetahuan } & \multicolumn{3}{c}{ Sex } \\
\hline & $\begin{array}{l}\text { Laki- } \\
\text { laki }\end{array}$ & Perempuan & Total \\
\hline Kurang & & 3 & 3 \\
Baik & 26 & 9 & 35 \\
\hline Total & 26 & 12 & 38 \\
\hline \multicolumn{2}{r}{ P Fisher $=$} & $0.026,<0.05$
\end{tabular}

Pada tabel ini didapatkan pada laki-laki sebanyak 28 orang dan pada perempuan sebanyak 12 orang. Terdapat hubungan yang bermakna antara jenis kelamin terhadap pengetahuan ( $P$ Fisher 0,026), sebagai mana terlihat pada tabel 8

Tabel 9: Distribusi usia terhadap perilaku

\begin{tabular}{llll}
\hline Perilaku & \multicolumn{3}{c}{ Usia } \\
\hline & $\mathbf{1 3 - 2 0}$ & $\mathbf{2 0 / >}$ & Total \\
\hline Kurang & 9 & 7 & 16 \\
Baik & 17 & 5 & 22 \\
\hline Total & 26 & 12 & 38 \\
\hline \multicolumn{5}{c}{ Chi square $=1,895$}
\end{tabular}

Pada tabel ini didapatkan pada usia 13- 20 tahun sebanyak 26 orang dan pada usia $>21$ tahun sebanyak 12 orang. Tidak terdapat hubungan yang bermakna antara usia terhadap kepatuhan ( $\mathrm{Chi}$ square 1,$895 ; P>0,05)$, sebagai mana terlihat pada tabel 9.

Tabel 10 : Distribusi usia terhadap sikap

\begin{tabular}{llll}
\hline Sikap & \multicolumn{3}{c}{ Usia } \\
\hline & $\mathbf{1 3 - 2 0}$ & $\mathbf{2 0 / >}$ & Total \\
\hline Tidak & & 1 & 1 \\
Patuh & 26 & 11 & 37 \\
\hline Total & 26 & 12 & 38 \\
\hline \multicolumn{5}{r}{ P Fisher $=0.316$} &
\end{tabular}

Pada tabel ini didapatkan pada usia 13- 20 tahun sebanyak 26 orang dan pada usia $>20$ tahun sebanyak 12 orang. Tidak terdapat hubungan yang bermakna antara usia terhadap sikap (P Fisher 0,316; $P>0,05)$, sebagai mana terlihat pada tabel 10 .

Tabel 11 : Distribusi usia terhadap pengetahuan

\begin{tabular}{llll}
\hline Pengetahuan & \multicolumn{3}{c}{ Usia } \\
\hline & $\mathbf{1 3 - 2 0}$ & $\mathbf{2 0 / >}$ & Total \\
\hline Kurang & & 3 & 3 \\
Baik & 26 & 9 & 35 \\
\hline Total & 26 & 12 & 38 \\
\hline Fisher $=0,026$ & & &
\end{tabular}

$\mathrm{P}$ Fisher $=0,026$

Pada tabel ini didapatkan pada usia 13- 20 tahun sebanyak 26 orang dan pada usia $>20$ tahun sebanyak 12 orang, Terdapat hubungan yang bermakna antara usia terhadap pengetahuan ( $P$ Fisher 0,$026 ; P<0,05)$, sebagai mana terlihat pada tabel 11

Tabel 12: Distribusi tingkat pendidikan terhadap kontraktur sendi lutut

\begin{tabular}{lcc}
\hline Kontraktur & \multicolumn{2}{c}{ Tingkat Pendidikan } \\
& Rendah & Tinggi \\
\hline Ya & 11 & 9 \\
Tidak & 7 & 11 \\
\hline Total & 18 & 20
\end{tabular}

Chi square 1,454; $P>0,05$

Tabel 13 : Distribusi tingkat pendidikan terhadap pelaksanaan terapi latihan

\begin{tabular}{lcc} 
Kontraktur & \multicolumn{2}{c}{ Tingkat Pendidikan } \\
\cline { 2 - 3 } $\begin{array}{l}\text { setelah } \\
\text { Terapi latihan }\end{array}$ & & \\
& Rendah & Tinggi \\
\hline Ya & 11 & 9 \\
Tidak & 7 & 11 \\
Total & 18 & 20 \\
\hline &
\end{tabular}

Chi square 1,$454 ; P>0,05$

Pada tabel ini didapatkan pasien-pasien yang sudah diajarkan terapi latihan, dimana yang paling banyak terjadi kontraktur adalah pada tingkat pendidikan rendah sebanyak 18 orang $(47,4 \%)$ dan pada tingkat pendidikan tinggi sebanyak 20 orang $(52,6 \%)$. Hal ini membuktikan bahwa tingkat pendidikan tidak berhubungan dengan terjadinya kontraktur. Hai ini sebagai mana terlihat pada tabel 5.6 dan tabel 5.7

Faktor-faktor yang mempengaruhi kekakuan sendi lutut:

- Perilaku / Malas :17 orang ( 44,7\%)

- Sikap/Ketidakpatuhan latihan :2 orang ( 5,3\%)

- $\quad$ Pengetahuan pasien :1 orang ( $2,6 \%)$

\section{DISKUSI}

Dari hasil penelitian ini diperoleh data pasien 81 kasus fraktur femur $1 / 3$ tengah yang ditatalaksana dengan operatif dan non operatif selama 2 tahun (2009-2011) yang dikumpulkan dari data rekam medis di RSUP M.Djamil Padang-Sumatera Barat, dimana 38 kasus yang memenuhi kriteria penelitian yaitu 20 kasus yang ditatalaksana dengan operatif dan 18 
kasus lain yang ditatalaksana non operatif. Hal ini disebabkan data pasien yang kurang lengkap, pasien usia $<13$ tahun, waktu setelah ditindak $<3$ bulan dan pasien meninggal. Insidensi gangguan muskuloskeletal sering dijumpai pada saat ini,terutama akibat trauma. Trauma paling sering adalah karena patah tulang femur. Pada penanganan patah tulang femur adalah operatif dan konservatif dimana tindakan operatif dilakukan Reduksi terbuka fiksasi dalam dan tindakan konservatif dilakukan pemasangan Perkins traksi. Dari kedua penanganan diatas, timbul masalahmasalah berupa nyeri, odem, dan keterbatasan lingkup gerak sendi (LGS). Dari masalah-masalah tersebut diatas, akan timbul salah satu komplikasi berupa kontraktur sendi lutut. Sedangkan kontraktur itu sendiri adalah hilangnya atau kurang penuhnya lingkup gerak sendi secara pasif maupun aktif karena keterbatasan sendi, fibrosis jaringan penyokong, otot dan kulit kontraktur merupakan suatu keadaan patologis tingkat akhir dari suatu kontraksi. Sedangkan penyebab utama kontraktur adalah tidak ada ataukurangnya mobilisasi sendi akibat suatu keadaan antara lain keseimbangan kekuatan otot, penyakit neuromuskular, penyakit degenerasi, luka bakar, luka trauma yang luas, fraktur, inflamasi, penyakit kongenital, ankilosis dan nyeri.

Kekakuan sendi lutut pada pasien post operatif sering terjadi apabila pergerakan dini dari sendi tidak dilakukan oleh pasien. Burnwell telah melakukan penelitian pada 127 orang pasien fraktur shaft femur dan ditatalaksana dengan fiksasi interna dan Connolly et al. serta Hardy melakukan penelitian pada 108 pasien fraktur femur yang ditatalaksana secara Perkins traksi. Kesimpulan yang didapatkan dari penelitian tersebut adalah bahwa risiko kekakuan sendi semakin kurang apabila pasien melakukan pergerakan dini pada sendi lutut pasca internal fiksasi dan perkins traksi ${ }^{13}$ Ernest dkk menyebutkan dalam penelitiannya yang membandingkan efek fiksasi interna dengan traksi, bahwa fiksasi interna memberikan keuntungan lebih baik dalam hal lama rawatan, lama waktu penyembuhan tulang serta kualitas pergerakan yang dihasilkan, dalam hal ini berhubungan dengan sendi. ${ }^{2}$ Hasil penelitian ini menunjukkan bahwa pada operatif sebanyak 15 pasien mendapatkan LGS yang penuh sedangkan 5 pasien mendapatkan LGS $90 \%$ atau lebih. Dibandingkan dengan pada non operatif dimana hanya 3 pasien yang mendapatkan LGS penuh. Sisanya, 15 pasien mendapatkan LGS kurang dari $90 \%$. Dengan demikian didapatkan kesimpulan bahwa penatalaksanaan pasien fraktur femur, untuk mendapatkan hasil LGS yang lebih baik, sebaiknya digunakan metoda ORIF. Ini sesuai dengan penelitian yang telah dilakukan oleh Poolman $\mathrm{dkk}^{3}$

Pada penelitian yang dilakukan oleh Mandrella pada Rumah Sakit de Kibuye di Rwanda, didapatkan bahwa pada saat pelepasan traksi pada pasien patah tulang paha, lututnya berada pada posisi fleksi 80-90o dan bisa digerakkan dan diluruskan sampai sendi lutut teregang penuh. ${ }^{14}$ Melihat kondisi demikian, apabila dibandingkan dengan keadaan yang didapatkan pada penelitian ini, kemungkinan besar yang menyebabkan perbedaan hasil yang didapatkan adalah kurangnya latihan otot yang dilakukan pada pasien setelah dipasang perkin traksi. Pasien sepertinya lebih sering membiarkan posisi kakinya demikian tapi melakukan latihan dini. Ini bisa menyebabkan timbulnya kekakuan sendi lutut setelah traksi dilepas. Perkin traksi memberikan efek yang baik bagi penyembuhan tulang paha yang patah. Terhadap kekakuan sendi lutut yang terjadi pasca pemasangan perkin traksi, itu bisa dicegah dengan melakukan mobilisasi dini setelah pasien dirawat di ruangan. Dengan menggerakkan lutut, adhesi patellofemoral dan adhesi kapsular bisa dicegah. Adhesi antara kalus dengan quadriceps femoris juga bisa diminimalisir. Dengan melakukan gerakan aktif setelah pemasangan perkin traksi pada otot yang melingkupi tulang yang patah, jembatan kalus dapat lebih cepat terbentuk. 7,11

Dari hasil penelitian kami mendapatkan 81 kasus dimana 38 kasus yang memenuhi kriteriakriteria penelitian yaitu 20 kasus ditatalaksana dengan operatif dan 18 kasus lagi ditatalaksana dengan non operatif. Disini membuktikan bahwa kasus-kasus fraktur femur $1 / 3$ tengah bisa banyak ditemukan, tetapi banyak yang tidak memenuhi kriteria-kiteria penelitian seperti kelengkapan status kurang lengkap. Pada hasil penelitian ini, kejadian kontraktur sendi lutut atau tidak berdasarkan usia tidak berbeda jauh, dimana kejadian kontraktur pada usia 13-20 tahun ditemukan 9 kasus $(23,7 \%$ ) dan pada usia $>21$ tahun ditemukan 11 kasus (28,9\%). Dari hal ini dapat disimpulkan bahwa kejadian kontraktur sendi lutut bisa terjadi pada usia berapapun.

Pada penelitian ini juga ditemukan kekakuan/ kontraktur sendi lutut banyak ditemukan pada laki-laki sebanyak 13 kasus (34,2\%) dan pada perempuan ditemukan kekakuan sendi lututnya sebanyak 7 kasus $(18,4 \%)$. Dari hasil diatas, kita bisa menyimpulkan bahwa kekakuan sendi lutut terjadi lebih banyak pada laki-laki, dimana kasus fraktur femur $1 / 3$ tengah lebih banyak ditemukan pada laki-laki. Hal ini mungkin lebih disebabkan kurang disiplinnya penderita untuk mobilisasi karena nyeri dan oedem. Dan pada penelitian ini ditemukan kekakuan sendi lutut pada operatif sebanyak 5 kasus $(13,2 \%)$ dan pada non operatif ditemukan sebanyak 15 kasus.( $39,5 \%)$. Disini terlihat bahwa Perkins traksi lebih banyak ditemukan kekakuan sendi lutut'. Hal ini sebenarnya tak terlepas dari kemungkinan karena pada ORIF atau Perkins traksi yang pada dasarnya bila dilakukan terapi latihan sebaik mungkin akan menyebabkan tidak terjadinya kekakuan sendi lutut. Ini sesuai dengan penelitian yang dilakukan oleh Mandrella pada Rumah Sakit de Kibuye di Rwanda.

Begitu juga dengan kemungkinan kontraktur atau tidak berdasarkan waktu setelah ditindak dengan kejadian kontraktur sendi lutut lebih banyak terjadi pada waktu $>3$ bulan setelah ditindak yang didapatkan 38 kasus. Hal ini menunjukkan bahwa pasien fraktur femur memerlukan beberapa waktu setelah tindakan supaya pasien bisa terapi latihan. Berdasarkan tingkat pengetahuan, kontraktur sendi lutut didapatkan pada tingkat pengetahuan yang baik $(97,4 \%)$. Hal ini disebabkan oleh perilaku yang malas untuk melakukan terapi latihan pada pasien.Berdasarkan tingkat pendidikan, paling banyak terjadi kontraktur sendi lutut yaitu pada tingkat pendidikan rendah sebanyak 18 orang $(47,4 \%)$ dan tingkat pendidikan tinggi sebanyak 20 orang $(52,6 \%)$. Hal ini membuktikan bahwa tingkat pendidikan tidak berhubungan yang bermakna pada terjadinya kontraktur sendi lutut. 


\section{Kesimpulan}

- Faktor-faktor yang mempengaruhi kontraktur sendi lutut pada penanganan fraktur femur secara operatif dan non operatif adalah perilaku yang malas 17 orang $(44,7 \%)$, Sikap yang tidak patuh 2 orang $(5,3 \%)$ dan Pengetahuan yang kurang 1orang ( $2,6 \%)$.

- Angka kejadian kontraktur sendi lutut pada laki-laki adalah yang terbanyak 34,2\%.

- $\quad$ Angka kejadian kontraktur sendi lutut banyak terjadi pada Perkins traksi sebesar 39,5\%

- $\quad$ Tidak ada hubungan bermakna pada angka kejadian kontraktur sendi lutut berdasarkan usia maupun tingkat pendidikan.

\section{Daftar Pustaka}

1. Rasjad C. Pengantar IImu Bedah Ortopedi, Bintang Lamumpatue, Ujung Pandang, 1992.

2. Apley. Dalam Buku Ajar Ortopedi dan fraktur Sistem Apley, Edisi 7, Editor : Edi Nugroho 1999.

3. Snell, Richard S. 1997. Neuro Anatomi Klinik. Jakarta. EGC

4. Gray's Anatomi. Human Anatomy. Diunduh dari http://www.theodora.com/anatomy// accesed on oktober 2011.

5. Djoko Simbardjo. Fraktur Batang Femur. Dalam: Kumpulan Kuliah IImu Bedah, Bagian Bedah FKUI.

6. Bringker MD. Reviuw Orthopaedics and Trauma. Houston, Texas Co, Philadelphia. 2001

7. Buxton RA. The Use of Perkins' Traction in the Treatment of Femoral Shaft Fractures. Journal of Bone and Joint Surgery. British Editorial Society of Bone and Joint Surgery. 1981
8. Dandy DJ. Essential Orthopaedics and Trauma. Edinburg, London, Melborue, New York: Churchill Livingstone, 1989.

9. Sjamsuhidajat $\mathbf{R}$ dan de Jong, Wim (Editor). Buku Ajar Ilmu Bedah Edisi 2. Jakarta: EGC.2009

10. Kottke FJ. Therapeutic exercise to maintain mobility. In : Krusen's Handbook of physical medicine and rehabilitation. Thieth ed. Philadelphia. WB Saunders Co. 1982; 398-401

11. Salter. Textbook of Disorders and injuries of the Musculoskeletal System. 2nd ed. Baltimore/London: Willians \& Wilkins, 1983.

12. Ernest A. Brav M.C, Vinnie H. Jeffress M.C. Fractures of the femoral shaft: A clinical comparison of treatment by traction suspension and intramedullary nailing. The American Journal of Surgery, Volume 84, Issue 1. July, 1952; 16-25.

13. Burnwell HN. Internal Fixation In The Treatment of Fractures of the Femoral Shaft. Injury Volume II, Issues 3. Elsevier: 1971; 235-244

14. Mandrella B. The conservative treatment of femur fractures by Perkins traction. Management in adverse situations. Unfallchirurg. 2002 Oct;105(10):923-31Harrelson J.M, Ortopedi Umum. Dalam Buku Ajar IImu Bedah Sabiston. Editor : dr. Devi H, Alih bahasa : De Petrus A, EGC, Jakarta, 1994.

15. Jergesen F.H, Ortopedi. Dalam IImu Bedah (Handbook of Surgery), Editor : Theodore R. Schrock, Alih bahasa : Adji Dharma, Petrus, Gunawan, EGC, Jakarta, 1995.

16. Poolman RW, Bhandari M. Chapter 62 - Femoral Shaft Fractures: What is the Best Treatment? Evidence Based Orthopeadics. 2009.

17. Rosenthal RE. Fracture and Dislocation of the Lower Extremity. In: Early Care of the Injured Patient, ed IV. Toronto, Philadelphia: B.C. Decker, 1990. 